\title{
Evaluation of the Trust in Physician Scale (TIPS) of primary health care patients in north-east Poland: a preliminary study
} \author{
EVA LENA STRANDBERG ${ }^{4, E, F}$, CECILIA FAGERSTRÖM ${ }^{5, \mathrm{D}, \mathrm{E}}$, TERESA PAWLIKOWSKA ${ }^{6, \mathrm{D}, \mathrm{E}}$ \\ ${ }^{1}$ Department of Primary Health Care, Medical University of Bialystok, Poland \\ ${ }^{2}$ Department of Public Health, Medical University of Bialystok, Poland \\ ${ }^{3}$ Medical Center Masuria, Poland \\ ${ }^{4}$ Department of Clinical Sciences Malmö, Family Medicine, Lund University, Sweden \\ ${ }^{5}$ Blekinge Institute of Technology, Karlskrona, Sweden \\ ${ }^{6}$ Health Professions Education Centre, Royal College of Surgeons in Ireland, Irleand
}

LUDMIŁA MARCINOWICZ ${ }^{1, A, D, F, G}$, JACEK JAMIOŁKOWSKI', C-E , ZBIGNIEW GUGNOWSKI ${ }^{3, \mathrm{~B}, \mathrm{E}, \mathrm{F}}$,

A - Study Design, B - Data Collection, C - Statistical Analysis, D - Data Interpretation, E - Manuscript Preparation, F - Literature Search, G - Funds Collection

Summary Background. Trust is a complex concept, difficult to study, but very important in a patient-family physician relationship. One of the measures used to assess interpersonal trust is a scale developed by Anderson \& Dedrick entitled the Trust in Physician Scale (TIPS). Objectives. The aim of the study was to assess the TIPS properties in relation to the age, gender, and health status of primary health care patients consulting family doctors and trainees in north-east Poland.

Material and methods. A cross-sectional study using the TIPS was conducted in primary health care units in north-east Poland. 120 patients ( 60 who came to see family doctors, and 60 who came to see trainees) were asked to participate in the survey.

Results. The Trust in Physician Scale has good reliability in primary care patients in north-east Poland (Cronbach's alpha coefficient was 0.90). Patients displayed statistically significant greater trust in family doctors than in trainees. A negative correlation was found between age and the trust scale $(r=-0.30 ; p=0.005)$; the younger the respondent, the higher trust in the physician, and conversely, a positive correlation between self-assessment of health and the trust scale $(r=0.3 ; p=0.003)$.

Conclusions. The Polish translation of the TIPS instrument performed well in terms of acceptability in the family medicine environment. It can be used to differentiate between the level of trust in family doctors and in trainees. A relation between age, sex, education level and self-assessment of health needs to be confirmed using a larger sample.

Key words: patient trust, doctor-patient relationship, the Trust in Physician Scale, questionnaire.

Marcinowicz L, Jamiołkowski J, Gugnowski Z, Strandberg EL, Fagerström C, Pawlikowska T. Evaluation of the Trust in Physician Scale (TIPS) of primary health care patients in north-east Poland: a preliminary study. Fam Med Prim Care Rev 2017; 19(1): 39-43, doi: 10.5114/fmpcr.2017.65089.

\section{Background}

Trust is a complex concept, difficult to define and study. On the basis of a systematic review of literature, Ozawa and Sripad identified 45 measures of trust referring to the following relationship types: doctor/nurse-patient, health systems, insurers, pharmacists, researchers and others (health information exchange and health promotion partnerships). The authors of the review found that questions related to trust were focused on eight areas: fidelity, competence, honesty, confidentiality, confidence, communication, system trust and fairness [1]. Some of these areas, e.g. confidentiality, honesty and communication, are the attributes of a good patient-practitioner relationship and can be a quality component of health care [2].

One of the measures used to assess interpersonal trust in a patient-physician relationship is a scale developed by Anderson and Dedrick entitiled the Trust in Physician Scale (TIPS) [3]. The authors of the scale define interpersonal trust as "a person's belief that the physician's words and actions are credible and can be relied upon" [3, p. 1092]. This definition treats trust as a process which occurs when relations between a physician and a patient take place.

A review of literature shows that the Trust in Physician Scale is used among patients with rheumatic diseases [4], among malaria patients [5], as well as in obstetrics and to evaluate patient trust in physicians of gynecology departments [6]. Studies concerning patients' trust in family doctors with the use of this scale are seldom [7]; however, such research is important, because "physician trust exhibits a strong association with satisfaction, having enough choice in selecting one's physician and willingness to recommend the physician" [8, p. 314]. Individual factors could also be of importance in the discussion of patients' trust. Factors associated with satisfaction with the consultation might also be related to both the patient's age, gender and health status and the competence of the physician. The social competence of physicians, including communication skills, seems to be very important in a patient-physician relationship [9]. Research concerning primary care patients in the South of England showed that the trust relationship between patients and health professionals was one component which could have an impact on patient safety [10]. Further work in the area of the trust patients have in relation to their family doctor is needed to elucidate the influence of their longitudinal relationship, where continuity is possible in, or encouraged by, the structure of the primary care health system.

\section{Objectives}

The aim of the study was to assess the TIPS properties in relation to the age, gender and health status of primary health care patients of family doctors and trainees in north-east Poland. 


\section{Research questions:}

- What is the difference in the level of patients' trust in family doctors and in trainees?

- What are the relations between the level of trust and the respondents' characteristics?

\section{Material and methods}

Two primary care surgeries in north-east Poland were purposively selected; the directors of the clinics agreed to participate in this study, and the sites hosted trainees. This survey-based study involved the patients of two family doctors and two trainees.

The study tool was 11 items in the Trust in Physician Scale (Table 1) [3]. The respondents provided their answers on a 5-point Likert scale: from 1 (strongly disagree) to 5 (strongly agree). Demographic data (age, sex, education) and self-assessment of health data were also collected.

\begin{tabular}{|c|c|c|c|}
\hline & Item & $\begin{array}{l}\text { Item-scale } \\
\text { correlation }\end{array}$ & $\begin{array}{l}\text { Cronbach's } \\
\text { alpha } \\
\text { measured } \\
\text { without the } \\
\text { question }\end{array}$ \\
\hline 1. & $\begin{array}{l}\text { I doubt that my doctor really } \\
\text { cares about me as a person* }\end{array}$ & 0.45 & 0.904 \\
\hline 2. & $\begin{array}{l}\text { My doctor is usually considerate } \\
\text { of my needs and puts them first }\end{array}$ & 0.70 & 0.891 \\
\hline 3. & $\begin{array}{l}\text { I trust my doctor so much that } \\
\text { I always try to follow his/her } \\
\text { advice }\end{array}$ & \begin{tabular}{|l|}
0.77 \\
\end{tabular} & 0.887 \\
\hline 4. & $\begin{array}{l}\text { If my doctor tells me something } \\
\text { is so, then it must be true }\end{array}$ & 0.79 & 0.886 \\
\hline 5. & $\begin{array}{l}\text { I sometimes distrust my doc- } \\
\text { tor's opinion and would like } \\
\text { a second one* }\end{array}$ & 0.73 & 0.888 \\
\hline 6. & $\begin{array}{l}\text { I trust my doctor's judgment } \\
\text { about my medical care }\end{array}$ & \begin{tabular}{|l|}
0.57 \\
\end{tabular} & 0.897 \\
\hline 7. & $\begin{array}{l}\text { I feel my doctor does not do } \\
\text { everything he/she should for } \\
\text { my medical care* }\end{array}$ & 0.43 & 0.910 \\
\hline 8. & $\begin{array}{l}\text { I trust my doctor to put my } \\
\text { medical needs above all other } \\
\text { considerations when treating } \\
\text { my medical problems }\end{array}$ & 0.80 & 0.885 \\
\hline 9. & $\begin{array}{l}\text { My doctor is a real expert in } \\
\text { taking care of medical problems } \\
\text { like mine }\end{array}$ & 0.81 & 0.883 \\
\hline 10. & $\begin{array}{l}\text { I trust my doctor to tell me if } \\
\text { a mistake was made about my } \\
\text { treatment }\end{array}$ & 0.59 & 0.896 \\
\hline 11. & $\begin{array}{l}\text { I sometimes worry that my doc- } \\
\text { tor may not keep the informa- } \\
\text { tion we discuss totally private* }\end{array}$ & 0.54 & 0.898 \\
\hline
\end{tabular}

* Reverse-scored items.

This instrument was used in the assessment of physician-patient trust in the obstetrics and gynecology departments in Poland [6]. In this study we obtained the instrument directly from one of its authors (Robert F. Dedrick) at the request of the first author (LM). It was translated professionally from American English into Polish and was then back-translated by another one of the authors (TP). Any remaining issues were resolved by discussion and a consensus within the team to produce the final Polish version.
120 questionnaires were distributed among the patients (60 for patients who came to see family doctors, and 60 for those who came to see trainees) in June 2016. The questionnaires were distributed by the nurses at the registration desks of the clinic. Patients filled in the questionnaires before their consultations with doctors, and 99 questionnaires (82.5\%) were returned and analyzed.

The summary measure of trust could have a value from $0-100$, with higher scores reflecting greater trust. The relation between the level of trust and a number of qualitative variables was measured using the Mann-Whitney $U$ test and the Krus$\mathrm{kal}-$ Wallis test. Correlations between the quantitative or ordinal characteristics and the scale and its particular components were assessed using the nonparametric Spearman's correlation $\left(r_{s}\right)$. The relations between the questions in the scale and the other variables were assessed using the chi-square test of independence. Statistical analyses were calculated using IBM SPSS Statistics 20.0 software. Hypotheses were verified at a 0.05 significance level. The study was approved by the Ethics Committee of the Medical University of Bialystok, Poland (Approval number: R-I-002/326/2016).

\section{Reliability}

All the corrected item-to-scale correlations were 0.43 or higher. Cronbach's alpha was 0.90 , indicating a high degree of internal consistency. The results of correlations between the questions and the scale and Cronbach's alpha values are presented in Table 1. At this stage of the analysis, questions 1, 5, 7 and 11 were reversed so that the direction of the relation would be in agreement with the entire scale. Questions no. 1 and 7 displayed the weakest correlation with the scale. Removing these two questions would increase the coefficient in comparison to 0.904 and 0.910 appropriately, i.e. improve internal consistency.

\section{Lack of responses to certain questions}

Out of the 99 respondents, 13 (13.1\%) did not answer at least one question relating to the scale; most missing answers were to questions with negation (no. 1, 5, 7, 11). Four respondents did not answer question 1, while questions 5, 7 and 11 were skipped by six respondents each.

\section{Results}

\section{Characteristics of the respondents}

Among the 99 respondents, the majority were women ( $67.7 \%, n=67$ vs. $32.3 \%, n=32$ men). The mean age was 47.52 (20-91 years); $85.9 \%(n=85)$ of the respondents were city residents and $14.1 \%(n=14)$ were rural. The vast majority of those studied were individuals with higher education $(48.5 \%, n=48)$, $29.3 \%(n=29)$ had secondary education, $15.2 \%(n=15)$ - vocational, and $7.0 \%(n=7)$ - elementary. As for self-assessment of health, 13.1\% $(n=13)$ declared very good health, 39.4\% $(n=$ $39)$ - good, 38.4\% ( $n=38)$ - average, $6.1 \%(n=6)-$ poor, and $3 \%$ $(n=3)$ - very poor. More than half $(52.5 \%, n=52)$ admitted to having chronic diseases.

\section{Comparison of the scale of trust depending on the physician (family doctor vs. family medicine trainee)}

It was found that patients displayed greater trust in family doctors than in trainees (Median: 83 and 71.6, respectively), and the difference was statistically significant $(p=0.005)$ (Table 2$)$. In the other comparisons of the trust scale, depending on the age, sex, education, place of residence, self-assessment of health and declared chronic disease, no statistically significant differences were found. 
Table 2. Comparison of the scale of trust - family doctor vs. family medicine trainee (Mann-Whitney U test)

\begin{tabular}{|l|l|l|l|l|l|l|l|}
\hline & $n$ & Mean & SD & Min. & Median & Max. & $\boldsymbol{p}$-value \\
\hline $\begin{array}{l}\text { Family } \\
\text { Doctor }\end{array}$ & 40 & 78.5 & 18.7 & 27.3 & 83.0 & 100.0 & 0.005 \\
\cline { 1 - 5 } Trainee & 46 & 69.7 & 17.6 & 22.7 & 71.6 & 100.0 & \\
\hline
\end{tabular}

\section{Correlations between the scale and age, education} and self-assessment of health

In these correlations, questions 1, 5, 7 and 11 were not reversed. A negative correlation was found between age and the trust scale $(r=-0.30 ; p=0.005)$, and a positive one between self-assessment of health and the trust scale $(r=0.3 ; p=0.003)$. The younger the respondent, the higher the trust in the physician (Table 3 ).

\section{Correlations between quantitative and ordinal characteristics and components of the scale}

The correlation between the characteristics and individual scale components indicates varied results (Table 3 ). A positive correlation was found between age and negative statements. The older the age, the greater agreement with these statements: "I doubt that my doctor really cares about me as a person" ( $r=$ $0.21 ; p=0.046)$; "I sometimes distrust my doctor's opinion and would like a second one" ( $r=0.22 ; p=0.034)$; "I feel my doctor does not do everything he/she should for my medical care" ( $r=$ 031; $p=0.002$ ); "I sometimes worry that my doctor may not keep the information we discuss totally private" ( $r=024 ; p=0.020)$.
A negative correlation was found between age and the statement "I trust my doctor's judgment about my medical care". The older the respondent, the less agreement with this statement $(r=-0.20 ; p=0.047)$.

Taking education into account, a negative correlation was found for the statements "If my doctor tells me something is so, then it must be true" ( $r=-0.23 ; p=0.024)$ and "I trust my doctor to put my medical needs above all other considerations when treating my medical problems" $(r=-0.23 ; p=0.025)$. The lower the education, the greater agreement with these statements.

As for self-assessment of health, the outcomes were consistent for all the questions included in the scale. Negative correlations were found for three out of four statements with double negation, which, however, is the result of reversed encoding of those variables. In these cases, the negative correlation actually means that the better self-assessment of health, the lower inclination to agree with the following statements: "I doubt that my doctor really cares about me as a person" $(r=-0.26 ; p=$ 0.011); "I sometimes distrust my doctor's opinion and would like a second one" $(r=-0.24 ; p=0.022)$; "I feel my doctor does not do everything he/she should for my medical care" ( $r=-0.29$; $p=0.005)$; "I sometimes worry that my doctor may not keep the information we discuss totally private" $(r=-0.24 ; p=0.022)$.

Positive correlations were found for two statements. The better self-assessment of health, the more agreement with the statements "My doctor is usually considerate of my needs and puts them first" $(r=0.29 ; p=0.004)$ and "My doctor is a real expert in taking care of medical problems like mine" $(r=0.20 ; p=0.044)$.

In addition, it was found that patients who had appointments with trainees more often felt that their physicians did not do all they could to provide them medical care than patients who had appointments with family doctors $(p=0.022)$ (Table 4).

\begin{tabular}{|c|c|c|c|c|c|c|}
\hline \multirow[t]{2}{*}{ Items } & \multicolumn{2}{|l|}{ Age } & \multicolumn{2}{|c|}{ Education } & \multicolumn{2}{|c|}{$\begin{array}{l}\text { Self-assessment } \\
\text { of health }\end{array}$} \\
\hline & $r$ & $p$-value & $r$ & $p$-value & $r$ & $p$-value \\
\hline Trust scale & -0.30 & $0.005^{*}$ & -0.05 & 0.658 & -0.31 & $0.003^{*}$ \\
\hline I doubt that my doctor really cares about me as a person & 0.21 & $0.046 *$ & -0.10 & 0.326 & 0.26 & $0.011 *$ \\
\hline My doctor is usually considerate of my needs and puts them first & -0.09 & 0.378 & -0.14 & 0.171 & -0.29 & $0.004^{*}$ \\
\hline I trust my doctor so much that I always try to follow his/her advice & 0.01 & 0.885 & -0.15 & 0.134 & -0.11 & 0.277 \\
\hline If my doctor tells me something is so, then it must be true & -0.03 & 0.767 & -0.23 & $0.024 *$ & -0.17 & 0.096 \\
\hline I sometimes distrust my doctor's opinion and would like a second one & 0.22 & $0.034^{*}$ & 0.05 & 0.606 & 0.24 & $0.022^{*}$ \\
\hline I trust my doctor's judgment about my medical care & -0.20 & $0.047 *$ & 0.00 & 0.983 & -0.25 & $0.015^{*}$ \\
\hline I feel my doctor does not do everything he/she should for my medical care & 0.31 & $0.002 *$ & 0.01 & 0.960 & 0.29 & $0.005^{*}$ \\
\hline $\begin{array}{l}\text { I trust my doctor to put my medical needs above all other considerations } \\
\text { when treating my medical problems }\end{array}$ & -0.03 & 0.735 & -0.23 & $0.025^{*}$ & -0.03 & 0.806 \\
\hline My doctor is a real expert in taking care of medical problems like mine & -0.14 & 0.179 & -0.17 & 0.099 & -0.20 & $0.044^{*}$ \\
\hline I trust my doctor to tell me if a mistake was made about my treatment & 0.02 & 0.838 & -0.12 & 0.227 & -0.14 & 0.175 \\
\hline $\begin{array}{l}\text { I sometimes worry that my doctor may not keep the information we dis- } \\
\text { cuss totally private }\end{array}$ & 0.24 & $0.020^{*}$ & 0.04 & 0.733 & 0.24 & $0.022^{*}$ \\
\hline
\end{tabular}

* Significant correlation $(p<0.05)$.

Table 4. Comparison of the distribution of responses to the question "I feel my doctor does not do everything he/she should for my
medical care" (chi-square test of independence)
\begin{tabular}{|l|l|l|l|l|l|l|} 
& Strongly disagree & Disagree & Neutral & Agree & Strongly agree & $p$-value \\
\hline Family Doctor $N=45(100.0 \%)$ & $19(42.2)$ & $10(22)$ & $7(15.6)$ & $5(11.1)$ & $4(8.9)$ & 0.022 \\
\hline Trainee $N=48(100.0 \%)$ & $7(14.6)$ & $22(45.8)$ & $5(10.4)$ & $7(14.6)$ & $(14.6)$ & \\
\hline
\end{tabular}

Table 5. Comparison of the distribution of responses to the question "I sometimes worry that my doctor may not keep the information we discuss totally private" (chi-square test of independence)

\begin{tabular}{|c|c|c|c|c|c|c|}
\hline & Strongly disagree & Disagree & Neutral & Agree & Strongly agree & $p$-value \\
\hline Family Doctor $N=45(100.0 \%)$ & $29(64.4)$ & $7(15.6)$ & $5(11.1)$ & $1(2.2)$ & $3(6.7)$ & \multirow[t]{2}{*}{0.022} \\
\hline Trainee $N=48(100.0 \%)$ & $18(37.5)$ & $21(43.8)$ & $5(10.4)$ & $3(6.3)$ & $1(2.1)$ & \\
\hline
\end{tabular}




\begin{tabular}{|c|c|c|c|c|c|c|}
\hline & Strongly disagree & Disagree & Neutral & Agree & Strongly agree & $p$-value \\
\hline $\begin{array}{l}\text { Woman } N=64 \\
(100.0 \%)\end{array}$ & $36(56.3)$ & $10(15.6)$ & $9(14.1)$ & $7(10.9)$ & $2(3.1)$ & \multirow[t]{2}{*}{0.036} \\
\hline $\begin{array}{l}\text { Man } N=31 \\
(100.0 \%)\end{array}$ & $10(32.2)$ & 13 (41.9) & $6(19.4)$ & $1(3.2)$ & $1(3.2)$ & \\
\hline
\end{tabular}

Patients who had appointments with trainees more often feared that their physicians would not keep confidential the information received from them than patients who had appointments with family doctors ( $p=0.022$ ) (Table 5).

Women reported that the physicians really cared about them as individuals more often than men $(p=0.036)$ (Table 6).

\section{Discussion}

The findings of our study prove that the Trust in Physician Scale has good reliability in primary care patients in north-east Poland. The internal consistency of the measure was high (0.90) [11] and was consistent with other studies [3, 4]. However, the possibility that negative questions may go unanswered must also be taken into consideration.

As suggested by our study, greater trust in a family doctor than in a trainee may be connected with the continuity of care. The results of qualitative studies carried out in four primary care research networks across Europe (Lodz, Cardiff, Tromso and Barcelona) indicate the value of continuity of care as the basis for the development of trust. These studies demonstrate that the continuity of care, open communication in consultations and doctor-patient trust were important in parents' acceptance of the management of respiratory tract infections in their children [12]. The observational questionnaire study conducted among 418 patients in the USA and 650 patients in the UK who were consulting family doctors suggest that trust in a regular doctor and consulting a regular doctor were the strongest predictors of patient satisfaction [7].

The differences in the level of patients' trust in family doctors and in trainees found in our study can also be considered in the context of patients' satisfaction with the care provided by their family doctors. Other qualitative studies show that having a regular family doctor is related to patient satisfaction with the doctor's care, and not having a regular family doctor, with dissatisfaction [13].

Our findings confirm that individuals with poorer health declare lower levels of trust than those with better health [4]. The outcomes are also in agreement with those obtained by Freburger et al., indicating that age correlates with the level of trust: the younger the age, the greater trust in a physician (Table 3 ).

A difference in the level of trust between men and women only occurred in the case of one question: "I doubt that my doctor really cares about me as a person". More women (56.3\%) than men (32.2\%) strongly disagree with this statement. Other studies using this scale also show that the level of trust in a physician is significantly higher in women [5].

\section{Limitations of the study}

The small sample framework is a limitation of the study. Patients at only two primary care surgeries and only two family doctors and two trainees were asked to participate. The pre-disposition of individual doctors, their inter-personal relationshipbuilding skills, regardless of specialty, also needs to be considered. Therefore, the possibility of interacting with a trainee who builds a significant degree of trust, relative to a family doctor, exists. If the trainee possessed excellent communication skills, then it is theoretically possible that this trainee would be highly valued by this scale and, in this small study, would have a disproportionate impact on the overall results. For this reason, further studies with a larger sample of patients, family doctors and trainees are indicated.

\section{Conclusions}

The assessment of trust in health care is complex. The Polish translation of the TIPS instrument performed well in terms of acceptability in the family medicine environment. This can be used to differentiate between the level of trust in family doctors and in trainees. A relation between age, sex, education level and self-assessment of health was demonstrated, but this needs to be confirmed using a larger sample.

Acknowledgements. This work was elaborated upon as a result of the Baltic Sea Region Primary Health Care Network. NORDISK.

Source of funding: This work was funded by project no. N/ST/ZB/16/006/3304 from the Medical University of Bialystok, Poland. Conflict of interest: The authors declare no conflict of interests.

\section{References}

1. Ozawa S, Sripad P. How do you measure trust in the health system? A systematic review of the literature. Soc Sci Med 2013; 91: 10-14.

2. Donabedian A. An introduction to quality assurance in health care. Oxford-New York: Oxford University Press; $2003: 19$.

3. Anderson LA, Dedrick RF. Development of the Trust in Physician Scale: a measure to assess interpersonal trust in patient-physician relationship. Psychol Rep 1990; 67(3 Pt. 2): 1091-1100.

4. Freburger JK, Callahan LF, Currey SS, et al. Use of the Trust in Physician Scale in patients with rheumatic disease: psychometric properties and correlates of trust in the rheumatologist. Arthritis Rheum 2003; 49(1): 51-58.

5. Van Damme-Ostapowicz K, Krajewska-Kulak E, Nwosu PJC, et al. Acceptance of illness and satisfaction with life among malaria patients in rivers state, Nigeria. BMC Health Serv Res 2014; 14: 202, doi: 10.1186/1472-6963-14-202.

6. Krajewska-Kulak E, Chilicka M, Kulak W, et al. Assessment of physician-patient trust in the obstetrics and gynecology departments in Poland and Greece. Ginekol Pol 2011; 82(12): 905-910.

7. Baker R, Mainous III AG, Gray DP, et al. Exploration of the relationship between continuity, trust in regular doctors and patient satisfaction with consultations with family doctors. Scand J Prim Health Care 2003; 21(1): 27-32.

8. Hall MA, Zheng B, Dugan E, et al. Measuring patients' trust in their primary care providers. Med Care Res Rev 2002; 59(3): 293-318.

9. Mroczek B, Zarek A, Rudnicki J, et al. Social competence of physicians and medical students - a preliminary report. Fam Med Prim Care Rev 2016; 18(3): 308-312. 
10. Ricci-Cabello J, Pons-Vigues M, Pujol-Ribera E, et al. Patients' perceptions and experiences of patient safety in primary care in England. Fam Pract 2016; 33(5): 535-542.

11. Tavakol M, Dennick R. Making sense of Cronbach's alpha. Int J Med Educ 2011; 2: 53-55.

12. Brookes-Howell L, Wood F, Verheij T, et al. Trust, openness and continuity of care influence acceptance of antibiotics for children with respiratory tract infections: a four country qualitative study. Fam Pract 2014; 31(1): 102-110.

13. Marcinowicz L, Grębowski R. Evaluation of family physician care in the light of qualitative studies: search for patients' satisfaction and dissatisfaction components. Fam Med Prim Care Rev 2008; 10(2): 173-179.

Tables: 6

Figures: 0

References: 13

Received: 18.11.2016

Revised: 19.12 .2016

Accepted: 20.12.2016

Address for correspondence:

Ludmiła Marcinowicz, PhD, Assoc. Prof.

Zakład Podstawowej Opieki Zdrowotnej UM

ul. Mieszka I 4 B

15-054 Białystok

Polska

Tel.: +48 85 732-68-20

E-mail: ludmila.marcinowicz@umb.edu.pl 